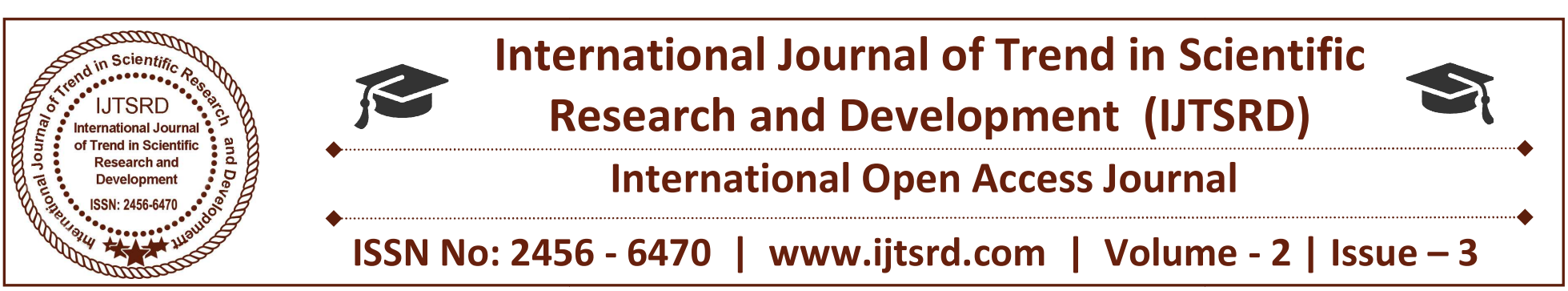

\title{
Biosynthesis of Eco-Friendly Silver Nano-Particles using Dry Fluted Pumpkin (TelfairiaOccidentalis) Leave Extractas Reducing Agent
}

\author{
Ihom P. Aondona \\ Department of Mechanical and Aerospace Engineering, University of Uyo, \\ Uyo PMB 1017 Uyo, Akwalbom State, Nigeria
}

\section{ABSTRACT}

The Biosynthesis of Eco-Friendly Silver NanoParticles using Dry Fluted Pumpkin (TelfairiaOccidentalis) Leave Extract as Reducing Agent was carried out. The research used the extract which was prepared from dry fluted pumpkin leaves to reduce $0.01 \mathrm{M}$ silver nitrate solution without the addition of any capping agent. During the biosynthesis process qualitative measures like 15 minutes interval observation for $1 \mathrm{hr}$., observation of precipitates formation, and laser light pointer were taken to establish the formation of AgNPs in the solution. The AgNPs for characterization were produced by allowing the biosynthesis solution to remain in the cardboard for 24 hours before filtering and drying the residue in the oven at $110^{\circ} \mathrm{C}$. The residue which was the AgNPs was characterized using ED-XRF and SEM. The NPs produced were of average size of $30 \mathrm{~nm}$ and angular and cubicle in shape. The chemical composition of the NPs was $71.8 \% \mathrm{Ag}_{2} \mathrm{O}, 25 \% \mathrm{SiO}_{2}, 2.18 \% \mathrm{Cl}$ and other trace compounds. The NPs; given the eco-friendly method of their biosynthesis can be further purified to be used on wound bandage.

Keywords: Reducing agent, Telfairiaoccidentalis, Nano-particles, Wound, Purity, Extract

\section{Introduction}

Manigandanet al., (2017), posited that " the unique physicochemical properties of nanomaterials are attractive for use in a variety of technologies due to the factors such as conductivity, magnetic property, and optical sensitivity by the characteristics such as small size, shape, surface structure and chemical composition. Modifying the properties of nanoscale materials generally involves control over the physicochemical features of the material. Noble metal nanostructures have created attention due to their extensive applicability in various domains. The advent of nanomaterials and their production sharpened man's precision in production especially the concept of top-down technique, from bulk to small and even smaller dimensions up to manufacturing molecule-to-molecule or even atom-to-atom and the bottom-up technique (Katsnelson, 2007; Preetha, and Rani, 2012; Obikwelu, 2012).

Silver (Ag) is a soft, translucent gray transition metal with an atomic number of 47 . This element has the highest thermal and electrical conductivity of all the metallic elements found so far on Earth. The electronic configuration of Silver is $[\mathrm{Kr}] 4 \mathrm{~d}^{10} 5 \mathrm{~s}^{1}$. It can be found in pure form or alloyed with other elements. It is considered a precious metal and is used for coins and bullions as part of monetary systems; it can be found in jewelry and ornaments. The photographic film industry has relied on the photochemical reactivity of silver and silver halide nanoclusters for many years to generate photographs (Poinern, 2015).

Because of its close association with human history in several applications, silver has also been tested and used in dentistry in the form of amalgams with mercury for fillings to repair tooth decay. In addition, silver compounds have long been known for their antimicrobial activity. With the advent of a plentiful supply of antibiotics after World War II, there has been a major shift away from metal ions and their antimicrobial effects (oligodynamic effects) until recently. As microbes can evolve, resistant bacterial 
strains, for example, are capable of handling the latest most potent generations of antibiotics, and coupled with their ability to pass on this resistance to others. It makes them formidable pathogens. Thus, there has been resurgence in the manufacture of nano-silver not only as an antibacterial, but also for potential application against fungi, viruses, and other pathogenic species. There is currently a drive to make nano-silver and apply it as coating for various medical components to stop infections. For instance silvernanoparticles sprayed bandages can be used to tie wounds to avoid bacterial infections. Scientist Robert Burrell created a process to manufacture antibacterial bandages using nanoparticles of silver. Silver ions block microbes' cellular respiration. In other words, silver smothers harmful cells killing them (Kuldeepet al., 2012;Biswas, et al., 2015; Shreya, et al., 2015; Benakashani, et al., 2016; Bansal, et al., 2017).

Here comes the issue of method of preparation; ecofriendly and harmless substances as reducing agents and capping chemicals are preferred. Any method therefore that will promote safer and purer form of silvernanoparticles for medical application will be a better option (Leela1 and Vivekanandan, 2008; Jannathul, and Lalitha, 2015; Selvam, et al., 2017). In this work the author intends to use fluted pumpkin (telfairiaoccidentalis)as both reducing agent and capping material for the production of pure AgNPs that can be applied as coating for various medical components to stop infections; including the treatment of wounds. No wonder the objective of the work which is the biosynthesis of AgNPs using ecofriendly approach of reducing with plant extract.

\section{Materials and Method}

\subsection{Materials}

The materials used for this work were; TelfairiaOccidentalis (Fluted Pumpkin), the extracts from the leaves were used as reducing agent, and $0.01 \mathrm{M}$ solution silver nitrate $\left(\mathrm{AgNO}_{3}\right)$ was used as the source of silver ions. Also used was milli-Qwater. The leaves used can be seen in fig. 1 below:

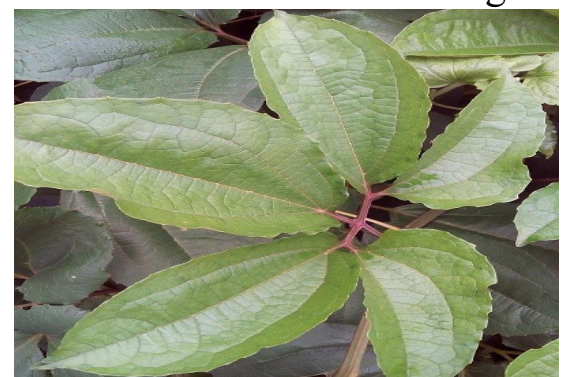

Fig. 1: TelfairiaOccidentalis (Fluted Pumpkin)

\subsubsection{Equipment}

The following equipment were used for the research work; $50 \mathrm{ml}$ measuring cylinder, $250 \mathrm{ml}$ beaker, 250 $\mathrm{ml}$ conical flask, filter paper, $20 \mathrm{ml}$ micropipette, micropipette tip, mortar and pestle, laser pointer. Digital camera, spatula, magnetic stirrer, hot plate (heater), $250 \mathrm{ml}$ reagent bottles, digital weighing balance; energy dispersive x-ray fluorescence (ED$\mathrm{XRF}$ ), Scanning Electron Microscope (SEM), blender, kimwipes, Buchner funnel, $50 \mathrm{ml}$ glass vials, and oven.

\subsection{Method}

\subsubsection{Dried leaves extract preparation}

Here the procedure varied slight from that of preparing extracts from fresh leaves. Fresh leaves of fluted pumpkin were collected from the University of Uyo, Biological Garden, the leaves were sun-dried after thoroughly washing them. They were again dried in the oven at $40^{\circ} \mathrm{C}$ for $24 \mathrm{hrs}$. The leaves were then blended using a blender. From the dried-processed leaves, $5 \mathrm{~g}$ was measured and transferred into $250 \mathrm{ml}$ beaker to which was poured $50 \mathrm{ml}$ milli-Q- water and boiled on the heating plate. The suspension was allowed to cool before it was poured into the funnel with filter paper to filter out the suspension. The extract was collected as filtrate in the beaker. See fig. 2 below:

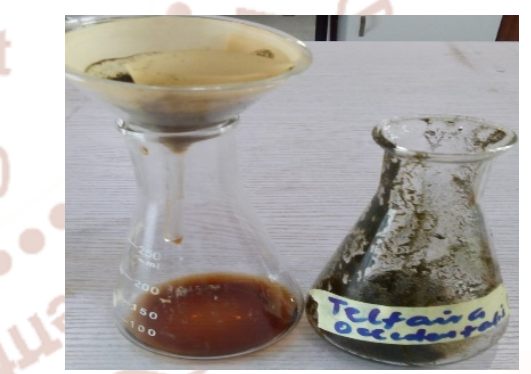

Fig. 2: Extract from Fluted Pumpkin (TelfairiaOccidentalis) Dried Leaves

\subsubsection{Bio-Synthesis of AgNPs using Extract of the Dried Leaves}

$180 \mathrm{~mL}$ of the dried leave extract of $T$. occidentalis was poured into $250 \mathrm{~mL}$ reagent bottle. Then $20 \mathrm{~mL}$ of $0.01 \mathrm{M} \mathrm{AgNO}{ }_{3}$ was poured into the reagent bottle containing $180 \mathrm{~mL}$ of the driedleave extract of telfairiaoccidentalis to synthesize the Ag NPs. After that, the mixture of the leave extract and $\mathrm{AgNO}_{3}$ was gently shaken for $2 \mathrm{~min}$ to have a uniform solution of the mixture. After shaking, the mixture was kept still and observed for any colour change after interval of $15 \mathrm{~min}$ for $60 \mathrm{~min}$. Laser beam from a laser pointer was used to observe if there was scattering of the light on the mixture as the beam of light passes through the 
bottle containing the $\mathrm{AgNO}_{3}$ solution to the bottle containing the mixture of the extract and the $\mathrm{AgNO}_{3}$ Solution..After observation for 60 mins the solution was allowed to stay for $24 \mathrm{hrs}$ resulting in more particles being formed; noticed through change of colour and quantity of residue on the filter paper. Fig. 3 captures the biosynthesis process of AgNPs using dried leaves of telfairiaoccidentalis extract.

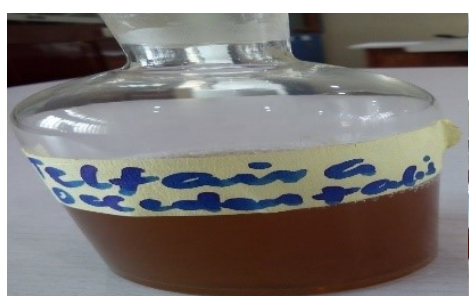

(a)

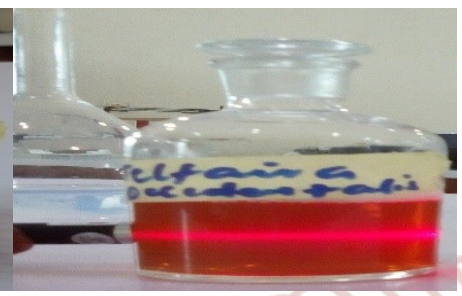

(b)

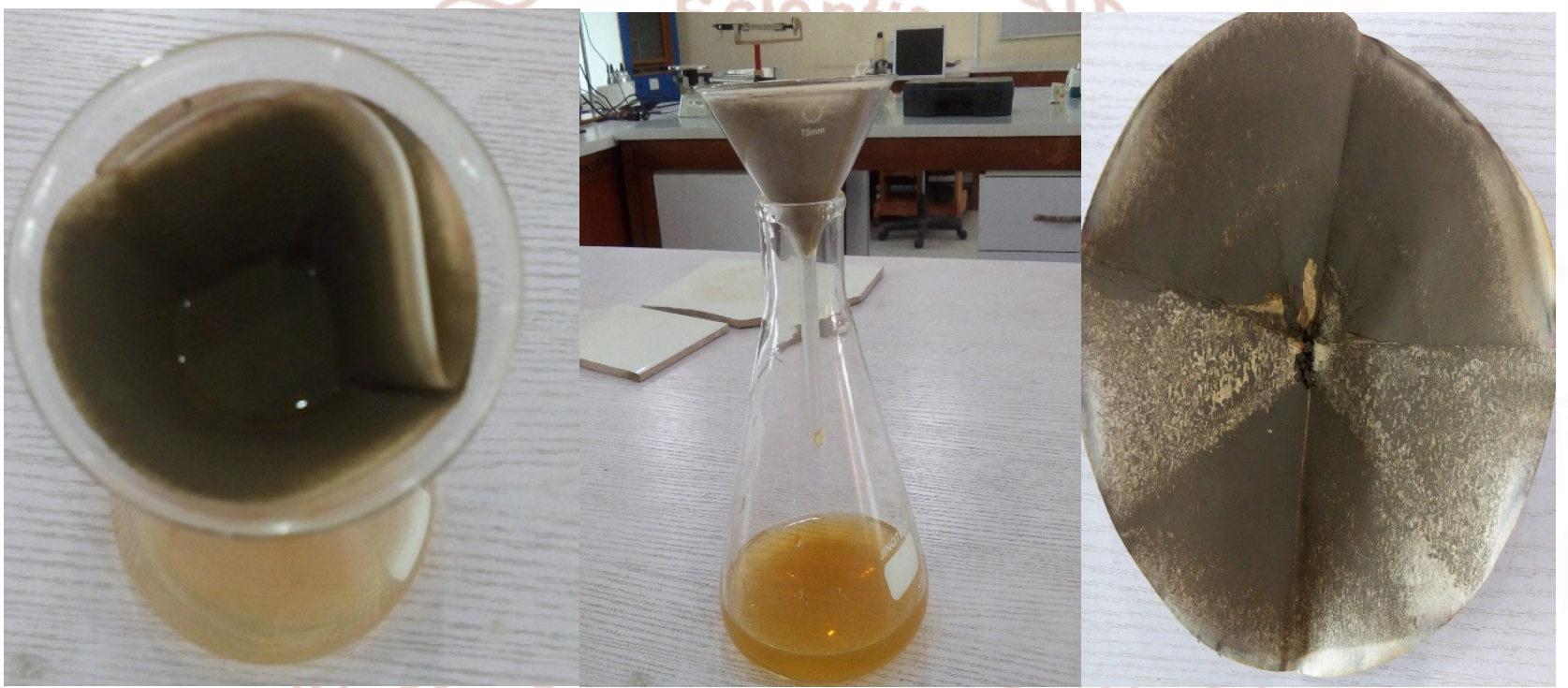

Fig. 4: Silver Nanoparticles from Dried Leaves of TelfairiaOccidentalis Extract without any Capping Agent.

\subsubsection{Characterisation of AgNPs Produced using TelfairiaOccidentalis (Fluted Pumpkin)}

SEM Analysis was carried out, with Phenom SEM Model Pro $\mathrm{x}$, on the AgNPs produced to identify the morphology, size and shape of the produced AgNPs. The chemical analysis of the AgNPswas performed by using Energy Dispersive X-Ray Flourescent, Mini pal4 ED-XRF model. The two tests were carried out at Nigeria Geological Survey Agency, Zaria, Kaduna.

\section{Results and Discussion}

\subsection{Results}

The results of the work are displayed as below; Table 1 gives the result of the AgNPs biosynthesis process, fig. 5 indicates colour at start of biosynthesis and colour change after 1 hour, Table 2 shows some properties during the biosynthesis process, Table 3 shows the chemical analysis of the AgNPs using ED-XRF, and fig.6 shows the SEM micrographs of the AgNPs. 
International Journal of Trend in Scientific Research and Development (IJTSRD) ISSN: 2456-6470

Table 1: Biosynthesis of Silver Nanoparticles using Dried TelfairiaOccidentalisLeaves Extract

\begin{tabular}{|l|l|l|}
\hline PROCEDURE & OBSERVATIONS & COMIVIENTS \\
\hline $\begin{array}{l}\mathbf{2 0} \mathbf{~ m L} \text { of } 0.01 \text { M AgNO } \\
\mathbf{1 8 0} \text {. Occidentalis leaves extract }\end{array}$ & No notable colour change & Initial time of reaction \\
\hline $\mathbf{1 5}$ min & Slight colour change & $\begin{array}{l}\text { Reduction reaction taking } \\
\text { place. }\end{array}$ \\
\hline $\mathbf{3 0}$ min & $\begin{array}{l}\text { Solution continue to become } \\
\text { darker }\end{array}$ & $\begin{array}{l}\text { Reduction } \\
\text { continues, which indicates } \\
\text { the formation of Ag NPs. }\end{array}$ \\
\hline $\mathbf{6 5}$ min & Slightly darker colour change & Formation of Ag NPs. \\
\hline $\begin{array}{l}\text { Testing with } \\
\text { Laser pointer } \\
\text { Light }\end{array}$ & No further colour change & Reduction reaction on \\
\hline
\end{tabular}

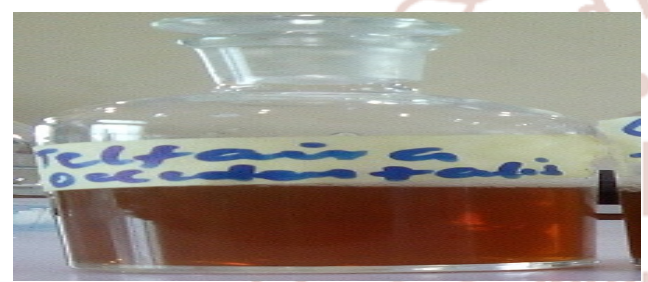

Fig.5a: Initial (Light Brown)

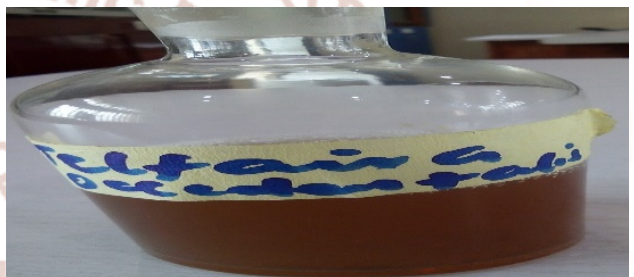

Fig.5b: Colour Change (Dark brownish)

Fig.5a and 5b Indicates the Colour Change of the Reaction Mixture of Silver Nitrate and Dried Leave Extract of T. Occidentalis.

\subsubsection{Some Properties of the Aqueous Solution during Biosynthesis}

Table 2: Electronic Conductivity, $\mathrm{pH}$ and Temperature during the Biosynthesis Process.

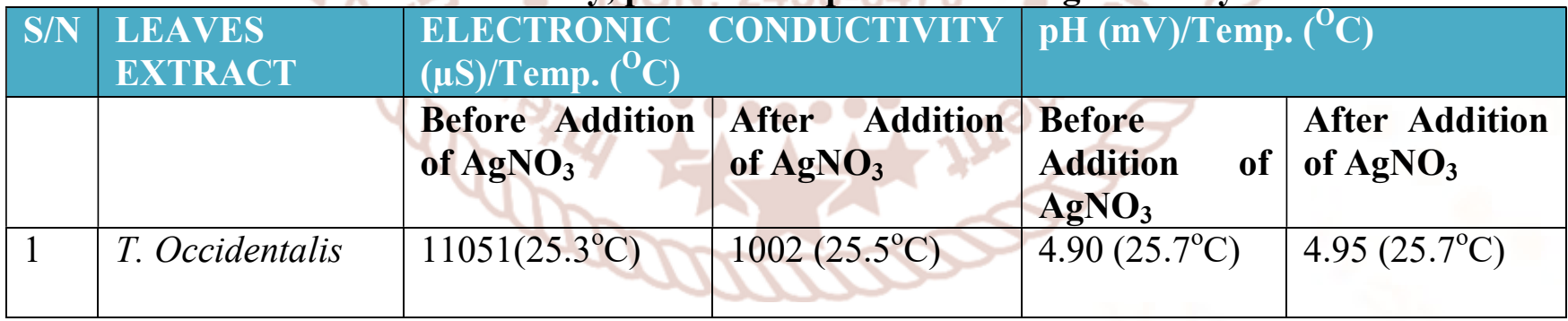

\subsubsection{AgNPs Analysis using ED-XRF}

Table 3: Result of ED-XRF analysis

\begin{tabular}{|l|l|}
\hline $\begin{array}{l}\text { CHEMICAL } \\
\text { COMPOSITION } \\
\text { (OXIDES) }\end{array}$ & $\begin{array}{l}\text { (\%) } \\
\text { COMPOSITION }\end{array}$ \\
\hline $\mathrm{SiO}_{2}$ & 25.00 \\
\hline $\mathrm{Cl}$ & 2.18 \\
\hline $\mathrm{MnO}$ & 0.098 \\
\hline $\mathrm{Fe}_{2} \mathrm{O}_{3}$ & 0.35 \\
\hline $\mathrm{NiO}$ & 0.035 \\
\hline $\mathrm{CuO}$ & 0.076 \\
\hline
\end{tabular}

\begin{tabular}{|l|l|}
\hline $\mathrm{Ag}_{2} \mathrm{O}$ & 71.80 \\
\hline $\mathrm{Yb}_{2} \mathrm{O}$ & 0.05 \\
\hline $\mathrm{Ga}_{2} \mathrm{O}_{3}$ & 0.007 \\
\hline $\mathrm{RuO}_{2}$ & 0.14 \\
\hline $\mathrm{Er}_{2} \mathrm{O}_{3}$ & 0.03 \\
\hline $\mathrm{HfO}_{2}$ & 0.003 \\
\hline $\mathrm{OsO}_{4}$ & 0.03 \\
\hline $\mathrm{IrO}_{2}$ & 0.028 \\
\hline $\mathrm{PbO}$ & 0.05 \\
\hline
\end{tabular}




\subsubsection{Scanning Electron Microscope Analysis}

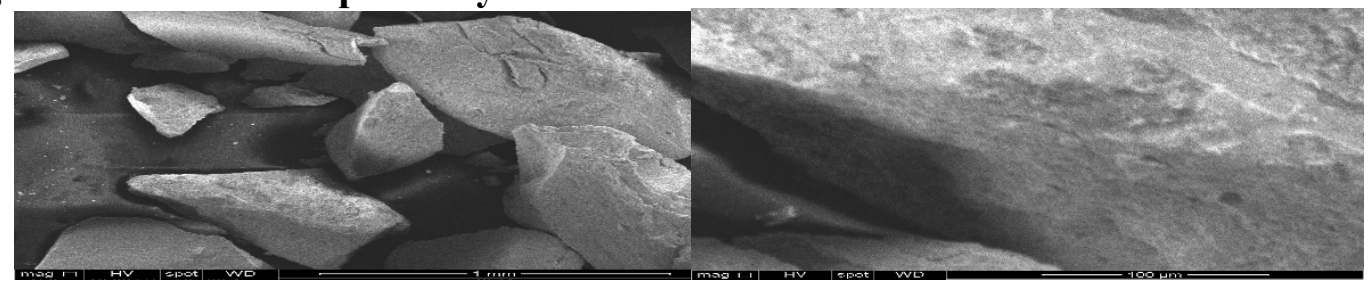

Fig.6: AgNPs Size and Shape at different Magnifications

\subsection{Discussion}

Table1 gives the result of the biosynthesis of AgNPs using dried leaves extract of telfairiaOccidentalis (fluted pumpkin). The initial colour of the biosynthesis solution was light brown; this colour continued to change after the interval of 15 minutes up to $1 \mathrm{hr}$, when it was completely changed to dark brown. See fig.5a and 5b. As the colour change was going on, precipitates were also sighted in the biosynthesis solution indicating that the extract was reducing the $\mathrm{Ag}+$ ions into $\mathrm{Ag}^{0}$ metal (http:// www.nanowerk.com 2012; Elnashaieet al., 2015; Manigandan, et al., 2017). The Laser light pointed at the solution revealed scattering in the biosynthesis solution. According to Poinern, I/ (2015), a one interesting property of colloidal particles, because of their shape and size, is that they scatter white light in a process called the Tyndall effect. Named after the nineteenth, Century Physicist John Tyndall, the effect is the process of light being scattered and reflected by colloidal particles or NPs in suspension. The presence of a colloidal suspension can be easily detected by the scattering/ reflection of a laser beam from the NPs as the beam of light passes through the solution. In contrast, when the laser beam is shined through a normal solution (i.e. silver nitrate solution) without colloids or NPs, the beam passes through without scattering. The Tyndall effect can only be used to determine if there are colloids/ NPs in that solution. Thus, it acts as a qualitative tool in the rapid determination of AgNPs in this instance because the human eye cannot directly see individual NPs in the solution.(Poinern, 2015) The method used in determining the formation of AgNPs agrees with above.

Table 2 gives the electronic conductivity, $\mathrm{pH}$, and temperature change before and during the biosynthesis of the AgNPs using telfairiaoccidentalis as the reducing agent.The electronic conductivity was $11051 \mu \mathrm{S}$ and this dropped to $1002 \mu \mathrm{S}$ in the biosynthesis solution; indicating that reduction of
$\mathrm{Ag}+$ ions to $\mathrm{Ag}^{0}$ was ongoing in the solution. The $\mathrm{pH}$ of the reducing agent which was 4.9 when added to

the $\mathrm{AgNO}_{3}$ solution; the $\mathrm{pH}$ of the biosynthesis solution became 4.95; reducing in acidity. The temperature change was not significant during the biosynthesis process. The potentials of leave extracts as a reducing agent for biosynthesis of AgNPs has been confirmed by several authors. In some plants, the acidic components can easily aid the reduction of the metallic ions. Furthermore, these studies showed that AgNPs created this way possesses good antimicrobial activity. The fact that no capping agent or templating agent is needed makes this chemical route an attractive one (Leela1 and Vivekanandan, 2008;Kuldeep, et al., 2012; Jannathul, and Lalitha, 2015; Biswas, and Dey, 2015;Benakashani, et al., 2016; Bansal, et al., 2017). No capping agent was used in this work except thetelfairiaoccidentalis extract which served as both reducing and capping agent.

The biosynthesis solution was hid in the cardboard for 24 hours before it was removed and filtered. The residue on the filter paper was dried in the oven at $110^{\circ} \mathrm{C}$ to produce dry AgNPs before it was sent for characterization. See Table 3 for the chemical composition of the AgNPs and Fig.6 for the morphology, size and shape of the silver nanoparticles which were produced using telfairiaoccidentalis as a reducing agent for silver nitrate solution. The optical property of silver NPs is tunable through the visible and near-infrared region of the spectrum as a function of NP size, shape, aggregation state, and local environment. The size and shape of the Silver NPs and the viewing conditions (transmitted light or reflected light) determine the colour of the silver solution that is ultimately obtained (Poinern, 2015). The average size of the NPs were $30 \mathrm{~nm}$ and they were mostly angular and cubicle in shape. The chemical composition showed that $\mathrm{Ag}_{2} \mathrm{O}$ was $71.8 \%$, $\mathrm{SiO}_{2}$ was $25 \%$ and Clwas $2.18 \%$, the other compounds were trace compounds. The instrument used for the 
analysis was calibrated to measure oxides and may have picked the oxygen from the surface of the NPs and not from the core of the NPs. The purity of the NPs can further be enhanced if for instance it is to be used for wound bandages.

\section{CONCLUSION}

This work has examined and studied the research work 'Biosynthesis of Eco-friendly Silver NanoParticles using Dried Fluted Pumpkin (telfairiaoccidentalis) Leaves Extract as Reducing Agent" the details of the conclusions drawn from this study are here presented:

i. The work has shown that dried fluted pumpkin leave extract can be used as a reducing agent without any capping to produce eco-friendly AgNPs.

ii. Laser light pointer, colour change and precipitates formation were qualitative proofs that the dried fluted pumpkin leave extract reduced the $\mathrm{Ag}+$ ions to $\mathrm{AgNPs}$.

iii. The chemical composition of the AgNPs showed that it contained $71.8 \% \mathrm{Ag}_{2} \mathrm{O}$; the purity of which can be increased by removing the $25 \% \mathrm{SiO}_{2}, 2.18 \% \mathrm{Cl}$ and other trace elements.

iv. The AgNPs produced were of the average size of $30 \mathrm{~nm}$

v. The AgNPs produced were angular and cubicle in shape.

vi. Given the friendly manner in which the particles were synthesized with further washing and purification they can be used on wound bandage.

\section{ACKNOWLEDGEMENTS}

The researchers of this work who are also the authors of this work wish to sincerely thank all who contributed in one way or the other in making this research work a reality. Our acknowledgement go to the following: Engr. Peter Asangasung, of the Chemical Engineering Laboratory, University of UyoNigeria and Analyst: E.D. Yaharo, Principal Lab. Superintendent I at NSRMEA Kaduna. Finally, we thank Engr. Nicholas Agbo of the DefenceIdustries Corporation of Nigeria.

\section{REFERENCES}

1. Bansal, P., Duhan, J.S. and Gahlawat, S. K., (2017) Biosynthesis of nanoparticles: A review, African Journal of Biotechnology, http://www.academicjournals.org/AJB

2. Benakashani, F., Allafchian, A.R, Jalali, S.A.H (2016), Biosynthesis of Silver Nanoparticles usingCapparisSpinosa L. Leaf Extract and their Antibacterial Activity, Karbala International Journal of Modern Science, Vol.2, Issue 4, 251258

3. Biswas, P. K., and Dey, S., (2015), Research Article Effects and Applications of Silver Nanoparticles in Different Fields, International Journal of Recent Scientific Research.Vol. 6, Issue, 8, pp.5880-5883.

4. Elnashaie S.S.,Danafar, F., andHashemipour, H., (2015), Nanotechnology for Chemical Engineers, Springer Science plus Business Media Singapore.

5. http://

www.nanowerk.com/nanotechnology/introduction I introduction to nanotechnology I. php, introduction to nanotechnology, accessed 2012.

6. Jannathul, M.F., and Lalitha, P. (2015) Biosynthesis of Silver Nanoparticle and its Application, Journal of Nanotechnology, Vol. 2015,1-18

7. Katsnelson, I. (2007) Graphene: Carbon in two Dimensions, Materials Today, vol.10. No 1-2.

8. Kuldeep, P., Pooja, K. and Rajesh, P. (2012) Recent Advances in Nanotechnology, International Journal of Scientific \& Engineering Research, vol.3, issue 11, 1-4

9. Leela1 A. and Vivekanandan M. (2008), Tapping the Unexploited Plant Resources for the Synthesis of Silver Nanoparticles, African Journal of Biotechnology Vol. 7 (17), pp. 3162-3165.

10. Manigandan, R., Praveen, K.S., Munusamy, S., Dhanasekarau, T., Padnanabau, A., Giribabu, K., Sresh, R. and Narayanan, V (2017) Green Biosynthesis of Silver Nanoparticles using Aqueous UrgineaIndica Bulbs Extract and their Catalytic Activity Towards 4-NP, MMS\&E Journal, 1-6

11. Obikwelu, D.ON. (2012) Nanoscience and Nanotechnology-An Introduction, $1^{\text {st }}$ Edition, Nigeria: De-Adroit Innovation Enugu,

12. Poinern, G.E.J. (2015) A Laboratory course in Nanoscience and Nanotechnology, $1^{\text {st }}$ Edition, London: CRC Press, Taylor \& Francis Group, pp95-101 
13. Preetha, N.K. and Rani, J. (2012) Nanokaolin Clay as Reinforcing Filler in Nitrile Rubber, International Journal of Scientific \& Engineering Research, vol.3, issue3, 1-5.

14. Selvam, K., Sadhakur, C, Goverthanan, M., Periasamy, T., Arumugam, S., Balakrishnan, S., Selvankumar, T. (2017) Eco-friendly Biosynthesis and Characterization of Silver Nanoparticles using TinosporaCordfolia(Thunb) Miers and Evaluate its Antibacterial, Antioxidant Potential, Journal of Radiation Research and Applied Sciences

15. Shreya, M., Amita, H, Uttiya, D, Paulomi, B, Naba, K.M. (2015) Biosynthesis of Silver Nanoparticles from Aloe Vera Leaf Extract and Antifungal Activity againstRhizopus sp. and Aspergillus sp., Springer, Applied Nanoscience, vol 5 , issue $7,875-880$ 